\title{
Growing Inorganic Membranes in Microfluidic Devices: Chemical Gardens Reduced to Linear Walls
}

\author{
Bruno C. Batista and Oliver Steinbock* \\ Department of Chemistry and Biochemistry, Florida State University, Tallahassee, Florida 32306-4390, USA
}

\section{Supporting Information}

\section{Description of the SI movies}

SI Movie 1: A precipitate membrane is formed inside a microfluidic device during the injection of $\mathrm{NaOH}$ and $\mathrm{MnCl}_{2}$ solutions (0.5 M each). The dimensions of the cell are $4 \times 5 \mathrm{~cm}^{2}$ and the channel has a width of approximately $3 \mathrm{~mm}$ and a height of $130 \mu \mathrm{m}$. The pump rate is $2 \mathrm{~mL} / \mathrm{h}$. The time-lapse movie is accelerated by a factor of 20 and shows a total of 10 min.

SI Movie 2: During the precipitate growth, small moving particles (diameter $<5 \mu \mathrm{m}$ ) are seen in the sub-channel that contains the manganese solution. In this experiment $[\mathrm{NaOH}]$ and $\left[\mathrm{MnCl}_{2}\right]=0.5 \mathrm{M}$ each. The pump rate is $2 \mathrm{~mL} / \mathrm{h}$. The movie shows a total of 9 s.

SI Movie 3: Temporal evolution of the membrane's width inside a microfluidic cell. In this experiment the reactant concentrations are $[\mathrm{NaOH}]=0.3 \mathrm{M}$ and $\left[\mathrm{MnCl}_{2}\right]=0.5 \mathrm{M}$. The pump rate is $2 \mathrm{~mL} / \mathrm{h}$. The time-lapse movie is accelerated by a factor of 600 and shows a total of $4 \mathrm{~h}$.

SI Movie 4: Methyl-orange $\left(3 \times 10^{-5} \mathrm{M}\right)$ can be adsorbed by the manganese precipitate. In this experiment a membrane is grown for $4 \mathrm{~h}$. The $\mathrm{NaOH}$ and $\mathrm{MnCl}_{2}$ solutions (both $0.5 \mathrm{M}$ ) are then exchanged for water and a methyl-orange solution, respectively. The new liquids are pumped for $10 \mathrm{~min}$ and then the flux is stopped. The initially dark colored channel, which contains the dye, gradually becomes clear. This process takes $40-60 \mathrm{~min}$ to complete. We then reinitialize the flow for $1 \mathrm{~min}$ and repeat the same cycle two more times. The pump rate is $8 \mathrm{~mL} / \mathrm{h}$. The time-lapse movie is accelerated by a factor of 600 and shows a total of $4 \mathrm{~h}$. 